\title{
Electrically Coupled Folded Arm Resonators with the Feedline Patch Antenna for Spurious Harmonic Suppression and Bandwidth Improvement
}

\author{
Mohammed Kadhim Alkhafaji \\ Southern Technical University (STU), Basra Technical Institute, Electronic Techniques Department, Iraq
}

Correspondence

* Mohammed Kadhim Alkhafaji

Southern Technical University (STU), Basra Technical Institute,

Electronic Techniques Department

Email:m.khudhair@stu.edu.iq

\begin{abstract}
This paper presents a new design of the filtering antenna with a quasi-elliptic function response. The basic structure of the proposed filtering antenna is consists of a four-folded arms open-loop resonator (OLR). The proposed filtering antenna is simulated, improved and, analyzed by using 3D Computer Simulation Technology (CST) electromagnetic simulator software. The design has good spurious harmonic suppression in the upper and lower stopbands. The Insertion Loss of the proposed filtering antenna $I_{L}=0.2 \mathrm{~dB}$ and the Return Loss $R_{L}=-25.788 \mathrm{~dB}$ at the center frequency $f_{o}=5.75 \mathrm{GHz}$. The passband bandwidth which is relatively wide, and equal to $0.793 \mathrm{GHz}$. The microstrip filtering antenna circuit shows good design results compared to the conventional microstrip patch antenna. The filtering antenna design circuit with etched ground plane structure also has good design results compared to the filtering antenna design which has a complete ground plane structure.
\end{abstract}

KEYWORDS: CST, filtering antenna, folded-arms OLR, patch antenna, quasi-elliptic function, spurious harmonic suppression.

\section{INTRODUCTION}

Microwave resonators and transmission lines such as waveguides and microstrip lines can be coupled in different ways to achieve microwave devices which used frequencyselective structures [1,2]. Coupling of transmission lines and resonators have many applications such as filters, filtering antennas, couplers, transformers, and other different devices. Open-loop and closed-loop resonators have been heavily studied and used in bandpass filters, antennas, filtering antennas, and other microwave circuits [2]. To reduce the interference and protect the sensitive receivers from reaching out-of-band signals, a wide stopband with a double mid-band frequency $\left(2 f_{o}\right)$ be required. Most planar bandpass filters and filtering antennas which consists of $\lambda_{g} / 2$ resonators, where $\lambda_{g}$ is a guided wavelength have a spurious passband at $2 f_{o}$ [3]. To suppress the spurious passband, cascaded lowpass filters or bandstop filters can be used. Microstrip Patch Antenna (MPA) is considered a suitable choice for narrowband microwave applications especially, wireless links that required semi-hemispherical coverage [4].

To design a feed-line microstrip filtering antenna there are three fundamental parameters should take into account and they are as follows:
- Suitable selection of the resonant frequency $\left(f_{o}\right)$.

- Suitable selection of the dielectric constant $\left(\varepsilon_{r}\right)$. The substrate dielectric constant is one of the most important design parameters. The dielectric substrate with a low dielectric constant is used to design the filtering antenna because; it gives perfect performance such as high bandwidth, better efficiency, and relatively low-quality factor Q [5].

- The height of the dielectric substrate thickness $(h)$, is used to design the filtering antenna.

Several Technologies have been investigated to suppress spurious responses such as the Defected Ground Structure (DGS) [6, 7], Stepped Impedance Resonator (SIR) [8].

This paper presents a new design of filtering antenna which is mainly based on the electrical coupling of the resonators and the microstrip feed-line. The proposed filtering antenna consists of four identical resonators, every two resonators are connected to form a single resonator on each side of the microstrip feed-line, which feeds a rectangular patch antenna. This technique contributes significantly to suppressed the spurious harmonics and improved the passband bandwidth. The proposed filtering antenna structure has a fractional bandwidth (FBW) of about $14 \%$ and centered at a mid-band frequency $f_{o}=5.75 \mathrm{GHz}$. This 
design shows an acceptable skirt selectivity and a wellshaped gain response. It exhibits reasonable efficiency of about $70 \%$ and a gain of about $2.85 \mathrm{~dB}$.

\section{FILTERING ANTENNA DESIGN}

The new design structure of the filtering antenna with a quasi-elliptic function response is proposed in this article. This design is depicted in Fig. 1, and the basic structure of the four-folded arms open-loop resonator (OLR) with its electrical lengths are depicted in Fig. 2 (a). Figure 2 (b) shows the equivalent circuit of folded arms OLR. This design is based on the electrical coupling of the feed-line patch antenna and the folded arm OLR. The presented design is consists of four identical folded arms OLR and microstrip patch antenna which feeds by microstrip feed-line. Every two resonators are connected to achieve the design requirements.

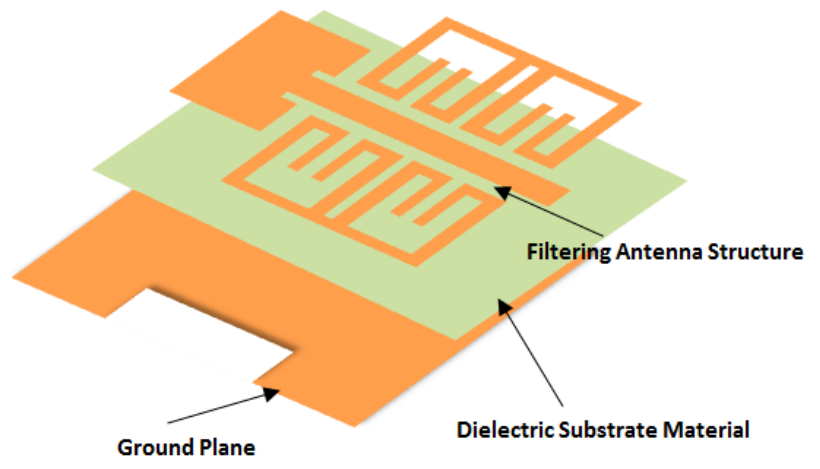

Fig. 1: Filtering antenna design structure.

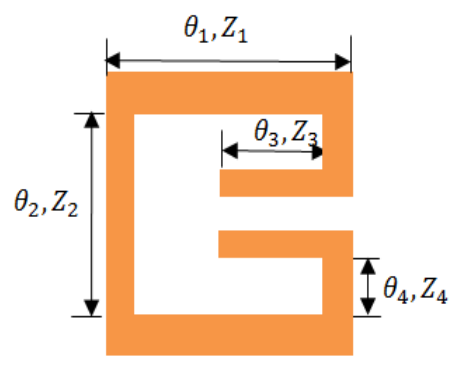

(a)

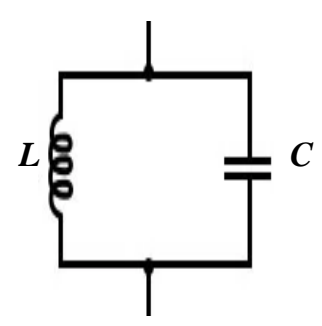

(b)
Fig. 2: Folded arms OLR (a) structure with its electrical lengths (b) equivalent circuit.

The equivalent circuit of the folded arms open-loop resonator is depicted in Fig. 2. The microwave model of the proposed filtering antenna design is depicted in Fig. 3. Before proceeding with the filter design, the design specifications should be stated carefully. With the assistant of these specifications, admittance inverters concerning characteristic admittance $J_{n} / Y_{o}(n=1,2, \ldots, N+1)$, and the shunt resonators $L_{n} C_{n}(n=1,2, \ldots, N)$ where $L_{n}$ are the shunt inductances, and $C_{n}$ are the shunt capacitances can be achieved in Ref. [9]. The specifications of the filter to be synthesized are a $3^{\text {rd }}$ order Chebyshev bandpass filter with a $0.2 \mathrm{~dB}$ equal-ripple $(\mathrm{N}=3)$. The characteristic impedance $Z_{o}=50 \Omega ;$ Fractional Bandwidth $(\mathrm{FBW})=0.14 ; f_{o}=$
5.75 $\mathrm{GHz}$. As the bandpass filter specifications are all now obtained.

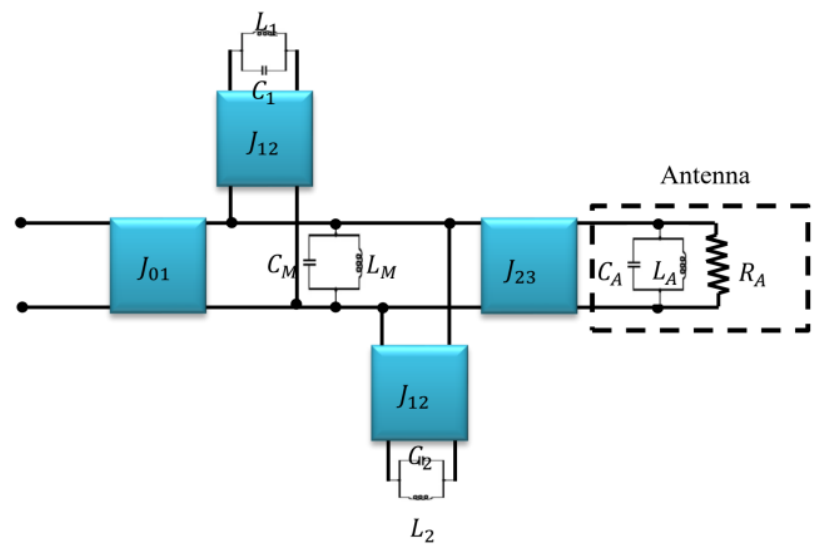

Fig. 3: The microwave model of the proposed filtering antenna.

The modification of wrapping arms of Fig. 2 (a) is used to decrease the size of hairpin resonators [10]. The folded arms structure can be created with minimal characteristic impedance $\left(Z_{o}\right)$ to design a model with a compact size. The microstrip folded arms OLR can be achieved by double folding a straight microstrip open resonator as depicted in Fig. 4 [11]. Because of the resonator corners and the fringing capacitance, an exact electromagnetic field calculation is impractical. Figure 5 shows the equivalent circuit of the straight open resonator which can be used to calculate the input admittance $\left(Y_{\text {in }}\right)$.

(a) Microstrip straight ope

(b) Folded arms OLR

Fig. 4: Folded arms OLR can be achieved by double The input admittance at any point of a straight open resonator length determines its resonant frequency.
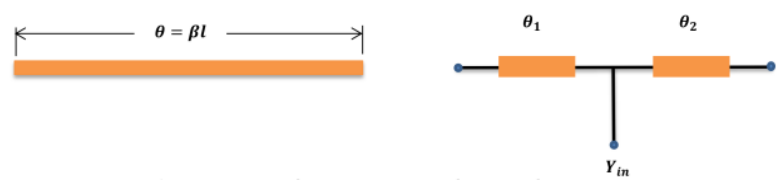

Fig. 5: Microstrip straight open resonator and its equivalent circuit.

The input admittance showed in Fig. 5 can be calculated as:

$$
Y_{\text {in }}=j Y_{o}\left(\tan \left(\theta_{1}\right)+\tan \left(\theta_{2}\right)\right.
$$

The total electrical length $\left(\theta_{T}\right)$ of a straight open resonator, $\theta_{T}=\theta_{1}+\theta_{2}$, where $\theta_{1}$ and $\theta_{2}$ are the electrical lengths of arm 1 and arn 2 respectively. A standing wave (SW), can be kept in the resonator, if $\boldsymbol{Y}_{\boldsymbol{i n}}=0$; so, an infinite resonance frequencies yields at:

$$
\theta_{\mathrm{T}}=\mathrm{n} \pi \quad \text { or } \quad \mathrm{l}=\mathrm{n} \chi / 2
$$


In the case of filter applications most interaction technique between resonators caused by proximity coupling which is called a coupling coefficient. The coupling coefficient mainly depends on the ratio of coupled energy to stored energy as shown below:

$$
k=\frac{\int \varepsilon E_{a} \cdot E_{b} d v}{\sqrt{\int \varepsilon E_{a}^{2} d v \int \varepsilon E_{b}^{2} d v}}+\frac{\int \mu H_{a} \cdot H_{b} d v}{\sqrt{\int \mu H_{a}^{2} d v \int \mu H_{b}^{2} d v}}
$$

Where the electric field $E_{a}$ and magnetic field $H_{a}$ are produced by the first resonator and $E_{b}, H_{b}$ fields are produced by the second resonator. The coupling coefficient $k(f)$ is an algebraic sum of two frequency-dependent expressions for two parallel $R L C$ resonant circuits. One of them is accountable for capacitive coupling and the other term represents inductive coupling [12]. The physical realization of narrowband filters did not have attenuation poles at the passband frequencies, and it depends on the numerical values of three kinds of quantities $f_{o}, Q$, and $k_{i, i+1}$, where $f_{o}$ is a resonant frequency, $Q$ is a quality factor of the resonator, and $k_{i, i+1}$ is a coupling coefficient of any two neighboring resonators. Thus the coupling coefficient is defined as:

$$
\mathrm{k} \approx \frac{\mathrm{f}_{\text {even }}-\mathrm{f}_{\text {odd }}}{\mathrm{f}_{0}}
$$

In a case of narrowband filters, the coupling coefficient can be defined as a constant calculated at a resonant frequency, so it can be carefully using a simplified approximate formula:

$$
\mathrm{k} \approx \frac{\mathrm{f}_{2}-\mathrm{f}_{1}}{\sqrt{\mathrm{f}_{1} \mathrm{f}_{2}}} \frac{1}{\sqrt{\mathrm{g}_{\mathrm{i}} \mathrm{g}_{\mathrm{i}+1}}}
$$

Where $f_{1}, f_{2}$ are the $3 \mathrm{~dB}$ passband edge frequencies, $g_{i}, g_{i+1}$ are the normalized elements of the lowpass filter prototype. Equation (5) can be derived for the microwave model of the filtering antenna shown in Fig. 3 as follows:

$$
\mathrm{k}_{\mathrm{i}, \mathrm{i}+1}=\frac{\mathrm{J}_{\mathrm{i}, \mathrm{i}+1}}{\sqrt{\mathrm{b}_{\mathrm{i}} \mathrm{b}_{\mathrm{i}+1}}}
$$

Where $\boldsymbol{J}_{\boldsymbol{i}, \boldsymbol{i}+\boldsymbol{1}}$ is the inverter admittance of the adjacent parallel-type resonators $i$ and $i+1$, and $b_{i}$ is the susceptance of $i$ th resonators. The susceptance $B_{i}(f)$ is equal to zero for all resonators at the resonant frequency $f_{0}$. The susceptance parameter can be calculated as:

$$
b_{i}=\left.\frac{f_{0}}{2} \frac{d B_{i}(f)}{d f}\right|_{f=f_{0}}
$$

The coupling coefficient $k$ at a resonant frequency is completely dependent on oscillation frequencies $f_{\text {odd }}$ and $f_{\text {even }}$ of two corresponding resonators. The coupling coefficient based on the above definition can be found as [12]:

$$
\mathrm{k}=\frac{\mathrm{f}_{\text {odd }}{ }^{2}-\mathrm{f}_{\text {even }}{ }^{2}}{\mathrm{fodd}^{2}+\mathrm{f}_{\text {even }}{ }^{2}}
$$

The loaded quality factor $Q_{L}$ is the actual quality factor that takes into account all the circuit losses. The loaded quality factor can be defined as a function of the external quality factor $Q_{e x}$ and the radiation quality factor $Q_{r}$ of the rectangular patch antenna as follows:

$$
\frac{1}{Q_{L}}=\frac{1}{Q_{e x}}+\frac{1}{Q_{r}}
$$

The value of the loaded quality factor can be measured directly. The technique used in this investigation to evaluate $Q_{r}$ is depend on the two-port microwave network depicted in Fig. 3 and can be calculated as:

$$
\mathrm{Q}_{\mathrm{r}}=\frac{\mathrm{c} \sqrt{\varepsilon_{\mathrm{re}}}}{4 \mathrm{f}_{0} \mathrm{~h}}
$$

Where $\mathrm{c}$ is light speed $\left(\mathrm{c}=3 \times 10^{8} \mathrm{~m} / \mathrm{s}\right), \varepsilon_{r e}$ is the effective dielectric constant of the substrate material, $h$ is the thickness of the substrate material. The suitable value of the external quality factor $Q_{e x}$ can be calculated by finding the suitable spacing between the feedline and the resonators, by using the following expression [13]:

$$
Q_{e x}=\frac{f_{o}}{f_{2}-f_{1}}=\frac{f_{o}}{\Delta f}
$$

The proposed filtering antenna shown in Fig. 6 occupies an overall size $45 \times 30 \mathrm{~mm}^{2}$ on the FR-4 substrate of the dielectric constant $\varepsilon_{r}=4.3$ and thickness $h=1.6 \mathrm{~mm}$. The filtering antenna has the following specifications; $f_{o}=5.75$ $\mathrm{GHz}, F B W=14 \%$, the return loss $R_{L}>-24 d B$, Insertion loss $I_{L}=0.2 \mathrm{~dB}$. The fractional bandwidth $F W B$ can be calculated as in Equation (12).

$$
F B W=\frac{\Delta f}{f_{o}}=\frac{f_{2}-f_{1}}{f_{o}}
$$

The admittance inverter values concerning $Y_{o}$ of Fig. 3 can be calculated as [14]:

$$
\begin{gathered}
\frac{\mathrm{J}_{01}}{\mathrm{Y}_{\mathrm{o}}}=\sqrt{\frac{\pi \mathrm{FBW}}{2 \mathrm{~g}_{\mathrm{o}} \mathrm{g}_{1}}} \\
\frac{\mathrm{J}_{\mathrm{i}, \mathrm{i}+1}=\frac{\pi \mathrm{FBW}}{\mathrm{Y}_{\mathrm{o}}}}{2 \sqrt{\mathrm{g}_{\mathrm{i}} \mathrm{g}_{\mathrm{i}+1}}} \text { for } i=1,2, \ldots \ldots, n \\
\frac{\mathrm{J}_{\mathrm{n}, \mathrm{n}+1}}{\mathrm{Y}_{\mathrm{o}}}=\sqrt{\frac{\pi \mathrm{FBW}}{2 \mathrm{~g}_{\mathrm{n}} \mathrm{g}_{\mathrm{n}}+1}}
\end{gathered}
$$

All design parameters of the proposed filtering antenna are stated in Table I. As mentioned earlier the filtering antenna design circuit is composed of four-folded arms OLR, every two resonators are connected on two opposite sides of the microstrip feed line which feeds the rectangular patch antenna. The design circuit of the filtering antenna with its optimized dimensions is depicted in Fig. 6. 
TABLE I

DESIGN PARAMETERS OF THE PROPOSED FILTERING

\begin{tabular}{|c|c|c|c|c|c|c|}
\hline$J_{01} / Y_{o}$ & $J_{12} / Y_{o}$ & $J_{23} / Y_{o}$ & $Q_{e x}$ & $Q_{L}$ & $Q_{r}$ & $k$ \\
\hline $\begin{array}{c}0.410 \\
8\end{array}$ & 0.17 & 0.140 & 7.03 & 4.63 & 13.61 & 0.023 \\
2 & 7 & 9 & 7 & 8 \\
\hline
\end{tabular}

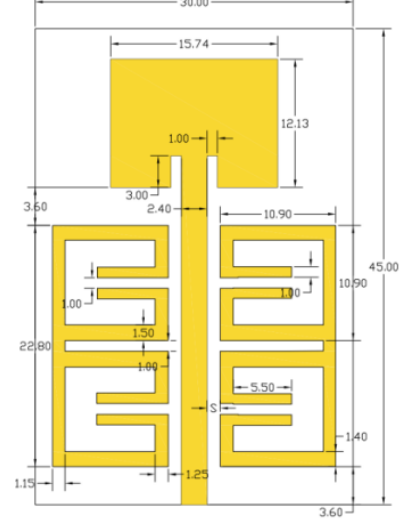

(a)

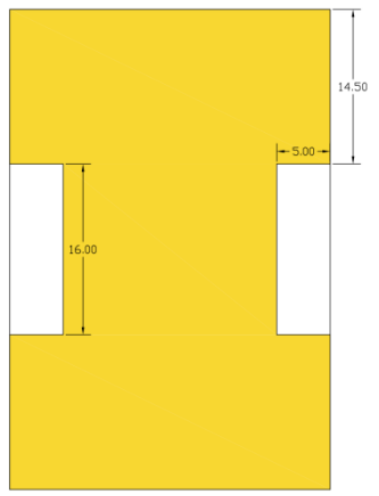

(b)
Fig. 6: Design circuit of the filtering antenna (a) Top view (b) Bottom view.

\section{SIMULATION RESULTS AND DISCUSSION}

The proposed filtering antenna is improved and analyzed by using 3D Computer Simulation Technology (CST) electromagnetic simulator software. The simulated $\mathrm{S}_{11}$ parameter of the filtering antenna is depicted in Fig. 7. The design has good spurious suppression in the stopband. The return loss is $-25.788 \mathrm{~dB}$ at the center frequency $f_{o}=$ $5.75 \mathrm{GHz}$. The passband bandwidth which is relatively wideband, and equal to $0.793 \mathrm{GHz}$ is one of the important reasons for designing the folded arms OLR filtering antenna. This bandwidth is capable of transmitting and receiving high-speed data rates. The filtering antenna has filtering and radiation functions simultaneously so, the gain often takes the same shape of the bandpass filter with quasi-elliptic function response, therefore, the upper and lower transmission zeros are located at $6.758 \mathrm{GHz}$ and $4.587 \mathrm{GHz}$ respectively. The gain over the passband of the proposed filtering antenna is shown in Fig. 8 is equal to $2.848 \mathrm{~dB}$. These results show a good matching between the folded arms OLR filtering antenna and the microstrip patch antenna.

Figure 9 shows the $S_{11}$-parameter of the folded arms OLR filtering antenna for various values of coupling space (s) between the resonator and the microstrip feed line.

From Fig. 9 it can be seen that increasing the value of coupling space leads to decreasing the $3 \mathrm{~dB}$ bandwidth, therefore the loaded quality factor will increase. It can be understood that any increase in the coupling space between the resonators and the feed line causes an improvement in the return loss, but increasing the value of (s) more than the critical value makes the coupling coefficient $k$ weak and then disturb the return loss $R_{L}$ [14]. The comparison between $\mathrm{S}_{11}$-parameter of the proposed filtering antenna and the conventional patch antenna is depicted in Fig. 10. Table II contains the comparison design parameters of the proposed filtering antenna and the conventional patch antenna [15].

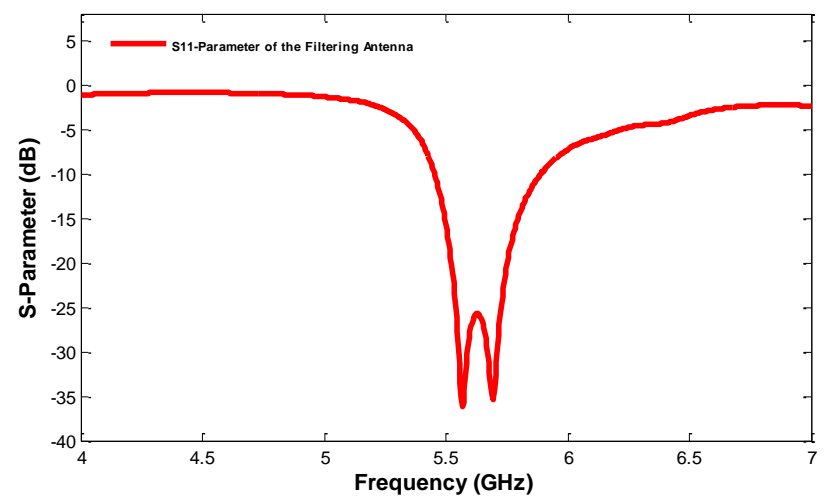

Fig.7: Simulated $\mathrm{S}_{11}$-parameter of the filtering antenna.

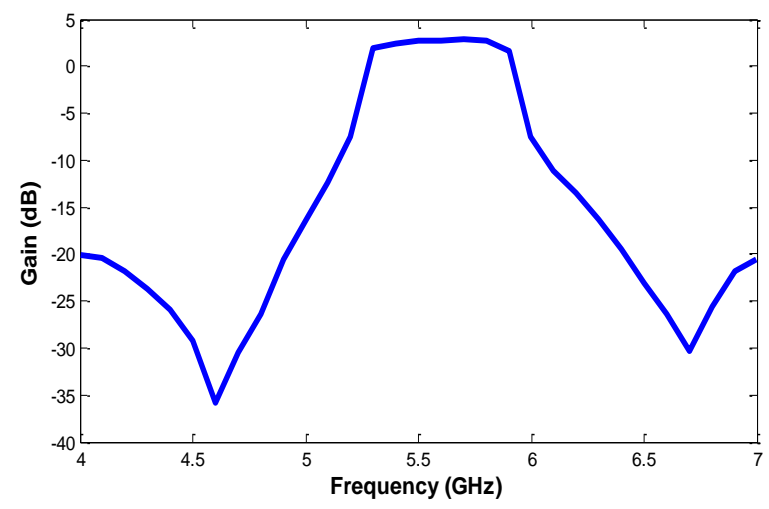

Fig. 8: Simulated gain of the proposed filtering antenna.

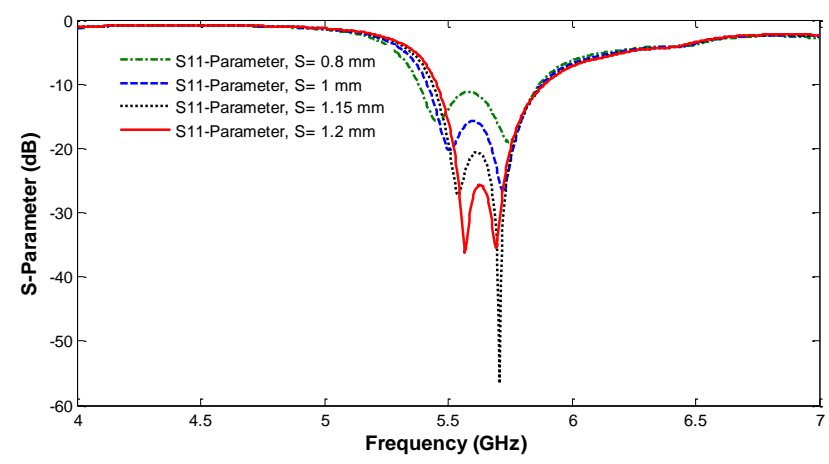

Fig. 9: $\mathrm{S}_{11}$-parameter of the filtering antenna for various values of coupling space (s).

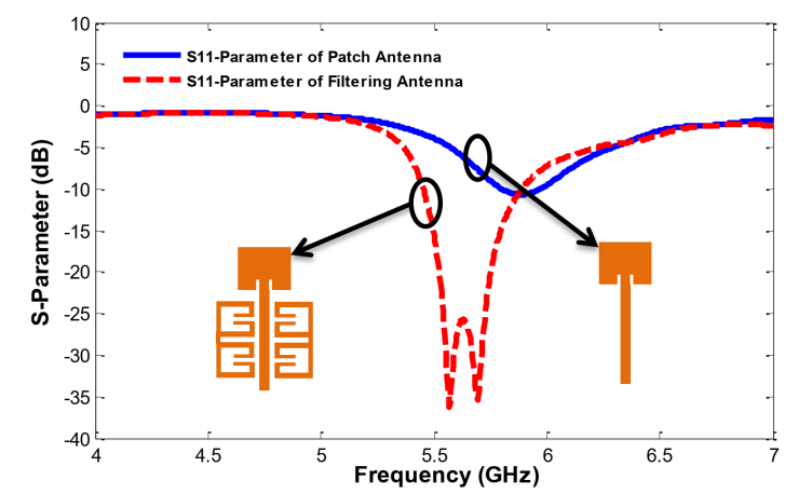

Fig. 10: $\mathrm{S}_{11}$-parameter of the conventional patch antenna and the proposed filtering antenna. 
TABLE II

COMPARISON DESIGN RESULTS OF THE CONVENTIONAL PATCH ANTENNA AND THE PROPOSED FILTERING ANTENNA.

\begin{tabular}{|c|c|c|}
\hline Parameter & $\begin{array}{c}\text { Conventional } \\
\text { Patch Antenna }\end{array}$ & $\begin{array}{c}\text { Filtering } \\
\text { Antenna }\end{array}$ \\
\hline $\begin{array}{c}\text { Center frequency } \\
f_{o}(\mathrm{GHz})\end{array}$ & 5.86 & 5.75 \\
\hline Return loss (dB) & -10.875 & -25.788 \\
\hline $\begin{array}{c}-10 \mathrm{~dB} \text { bandwidth } \\
\text { (MHz) }\end{array}$ & 176 & 437 \\
\hline $\begin{array}{c}\text { Voltage Standing } \\
\text { Wave Ratio (VSWR) }\end{array}$ & 1.74 & 1.1 \\
\hline Gain (dB) & 1.04 & 2.85 \\
\hline
\end{tabular}

The simulated power efficiency of the filtering antenna is depicted in Fig. 11. The proposed folded arms OLR filtering antenna using an etched ground plane on the two-sided of the ground plane structure. The incomplete ground plane structure is used to improve the design performance compared to the filtering antenna which used the complete ground plane structure as shown in Fig. 12. The 3D view surface current distribution and the 3D view far-field radiation pattern of the proposed filtering antenna is depicted in Fig. 13 and Fig. 14 respectively.

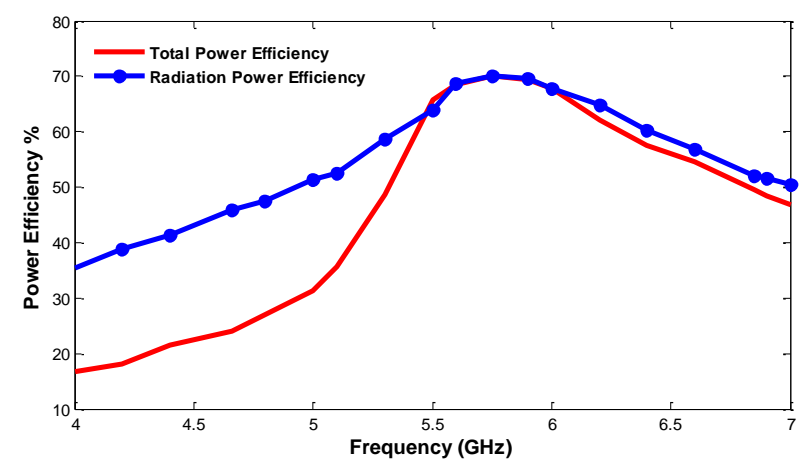

Fig. 11: Power efficiency of the proposed filtering antenna.

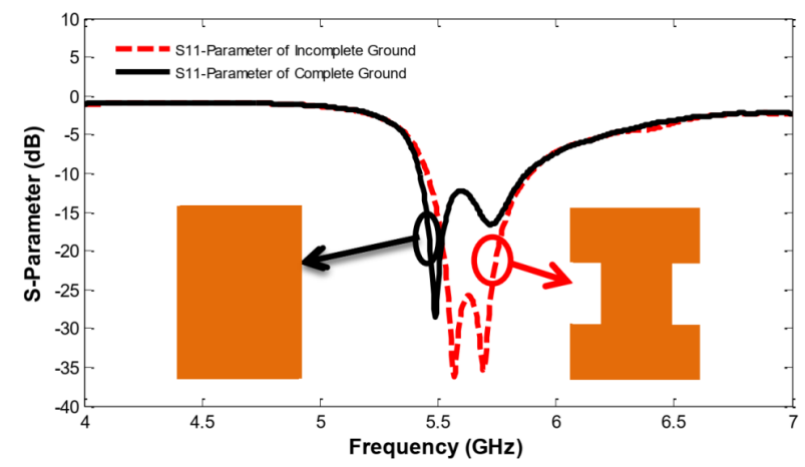

Fig. 12: $\mathrm{S}_{11}$-parameter of the complete and incomplete ground plane structure of the filtering antenna.

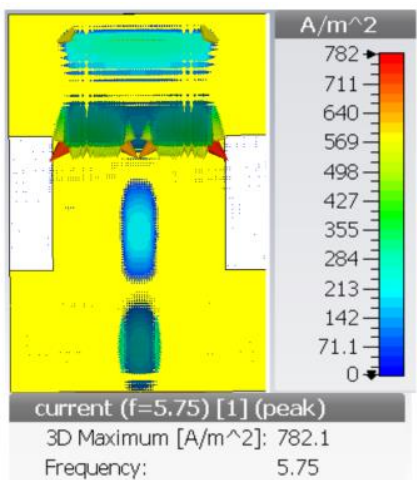

(a)

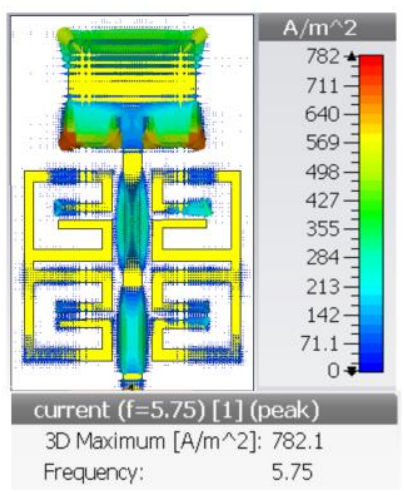

(b)
Fig. 13: 3D view of the surface current distribution of the filtering antenna (a) Bottom view (b) Top view.

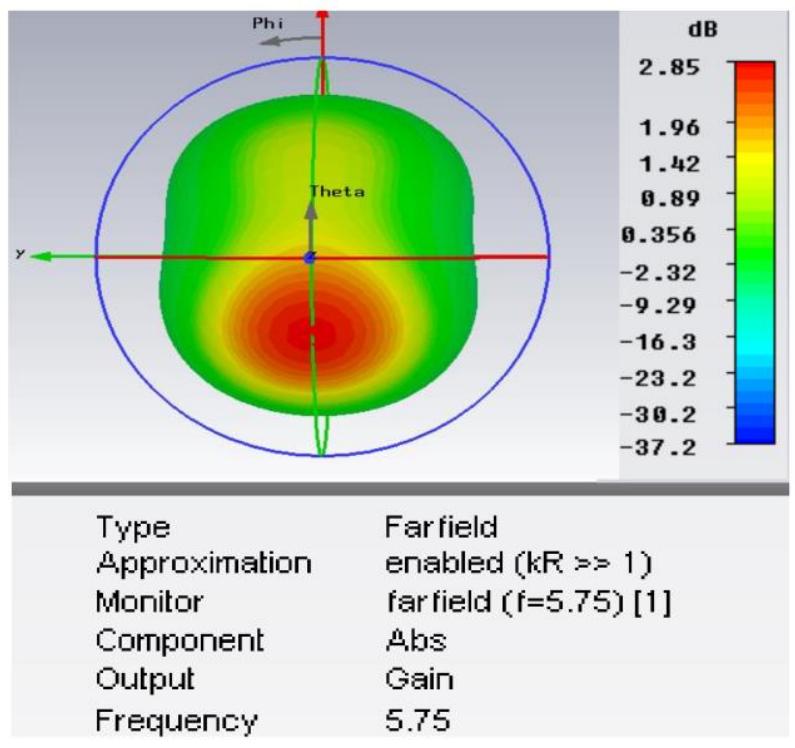

Fig. 14: 3D view of the far-field radiation pattern of the filtering antenna.

\section{CONCLUSIONS}

This paper presents a four-folded arms microstrip open-loop resonator filtering antenna design technique. This design is simulated and analyzed by using CST software technology on FR-4 epoxy dielectric substrate material has a relative permittivity $\varepsilon_{r}=4.3$ and $h=1.6 \mathrm{~mm}$. The proposed filtering antenna design has good spurious suppression in the stopband, also has a relatively wide passband bandwidth of about $793 \mathrm{MHz}$. The filtering antenna with a quasi-elliptic function response has two transmission zeros near the passband located at $4.587 \mathrm{GHz}$ and $6.758 \mathrm{GHz}$. The microstrip filtering antenna circuit shows good design results compared to the conventional microstrip patch antenna. The filtering antenna design circuit with etched ground plane structure also has good design results compared to the filtering antenna design which has a complete ground plane structure. 


\section{CONFLICT OF INTEREST}

The authors have no conflict of relevant interest to this article.

\section{REFERENCES}

[1]A. Abramowicz, "Unified description of coupled resonators and coupled transmission lines," ACTA Phys. Polonica A, vol. 119, pp. 548-552, 2011.

[2] S. Luo, L. Zhu, and S. Sun, "A dual-band ring-resonator bandpass filter based on two pairs of degenerate modes," IEEE Transactions on Microwave Theory and Techniques, vol. 58, pp. 3427-3432, 2010.

[3] J. S. Hong and M. J. Lancaster, "Theory and experiment of novel microstrip slow-wave open-loop resonator filters," IEEE Transactions on Microwave Theory and Techniques, vol. 45, pp. 2358-2365, 1997.

[4] I. Singh and V. Tripathi, "Microstrip patch antenna and its applications: a survey," Int. J. Comp. Tech. Appl, vol. 2, pp. 1595-1599, 2011.

[5] A. H. Reja, "Study of microstrip feed line patch antenna," Engineering and Technology Journal, vol. 27, pp. 355361, 2009.

[6] Y. Fu and N. Yuan, "Reflection phase and frequency bandgap characteristics of EBG structures with anisotropic periodicity," Journal of Electromagnetic Waves and Applications, vol. 19, pp. 1897-1905, 2005.

[7] L. Alfano, A. D'Orazio, M. De Sario, V. Petruzzelli, and F. Prudenzano, "A continuous varying impedance passband microstrip filter exploiting a butterfly wing shape," Journal of Electromagnetic Waves and Applications, vol. 19, pp. 1145-1156, 2005.

[8] J. Zhang, J.-Z. Gu, B. Cui, and X.-W. Sun, "Compact and harmonic suppression open-loop resonator bandpass filter with tri-section SIR," Progress In Electromagnetics Research, vol. 69, pp. 93-100, 2007.

[9] J. B. Jadhav and P. J. Deore, "Filtering antenna with radiation and filtering functions for wireless applications," Journal of Electrical Systems and Information Technology, vol. 4, pp. 125-134, 2017.

[10] A. V. V. Mannam and B. Y. R. Veeranki, " Design of Narrowband Band Pass Filter using Open-loop Square Resonators with Loading Element " Indian Journal of Science and Technology, vol. 9(47), pp. 1-9, 2016.

[11] Luis M. Ledezma," A Study on the Miniaturization of Microstrip Square Open Loop Resonators," University of South Florida, Thesis, 2011.

[12] V. V. Tyurnev "Coupling Coefficients of Resonators in Microwave Filter Theory," Progress In Electromagnetics Research B, Vol. 21, pp. 47-67, 2010

[13] Z. Brito-Brito, I. Llamas-Garro, G. Navarro-Munoz, J. Perruisseau-Carrier, L. Pradell, F. Giacomozzi, S. Colpo, " Precise frequency and bandwidth control of switchable microstrip bandpass filters using a diode and micro-electro-mechanical system technologies", IET Microwave Antennas Propagation, pp. 1-7, 2012.

[14] Mohammed K. Khudhaier, "Single-Band and DualLBand Microstrip Filter-Antenna for Wireless
Applications", Universiti Putra Malaysia, thesis, 2017.

[15] Ahmad A. Salih, Abdulkareem S. Abdullah, "Design and Analysis of a Single-Band Printed Rectenna Circuit at WiFi Frequency for Microwave Power Transmission", Iraqi Journal for Electrical and Electronic Engineering, Vol. 15, No. 2, 2019. 